\title{
Recombinant Angiogenin
}

National Cancer Institute

\section{Source}

National Cancer Institute. Recombinant Angiogenin. NCI Thesaurus. Code C1002.

A $14 \mathrm{kD}$ non-glycosylated human derived angiogenesis factor, which has the ability to

induce neovascularisation with a unique ribonucleolytic activity. ( $\mathrm{NCl}$ ) 